\title{
An ethical analysis of economic issues related to the appreciation of Renminbi
}

\author{
Wei Yang • Kit-Chun Joanna Lam
}

Published online: 28 May 2011

(C) Springer Science+Business Media B.V. 2011

\begin{abstract}
Since the outbreak of the global financial crisis in 2008, the exchange rate between China and USA has drawn a lot of attention. Because of the balance of payments surplus, China has accumulated a large amount of foreign exchange reserves, and there is much pressure on the Renminbi (RMB) to appreciate. The appreciation of RMB has raised a series of intertwining economic and ethical concerns in China. This paper is an inter-disciplinary study to illustrate the interrelationship between economics and ethics. We analyze the major economic factors affecting the trend of exchange rate of RMB and the effects of its appreciation. We then discuss the ethical implications of the appreciation and conclude with some policy suggestions to address the economic and the ethical concerns.
\end{abstract}

Keywords Economic ethics $\cdot$ Renminbi $\cdot$ Exchange rate $\cdot$ Appreciation

\section{Introduction}

In an open economy, the effect of exchange rate on external trade and other economic institutions has drawn much attention among scholars in China and other countries alike. According to macroeconomic theory, given some standard assumptions, changes in exchange rate will affect the price of domestic goods relative to the price of foreign goods, and thus, the pattern of expenditures will be affected. In general, a depreciation of the domestic currency can stimulate exports while discouraging imports. If the demand for imports and exports are price elastic, there will be an improvement in the balance of trade. In China, the depreciation of

\footnotetext{
W. Yang

Shanghai Academy of Social Sciences, Shanghai, China

e-mail: weiyang2009@sass.org.cn
}

K.-C. J. Lam ( $\bowtie)$

Hong Kong Baptist University, Hong Kong, China

e-mail: kclam@hkbu.edu.hk 
Renminbi (RMB) in the 1990s resulted in an observable effect on the balance of payments deficit. The relatively cheap exports gave China a competitive advantage, and the balance of payments deficit turned into a surplus within a short time, accompanied by an accumulation of official foreign exchange reserves. In recent years, the accelerated appreciation of RMB has not resulted in a decline in the volume of exports, while USA has not achieved the expected improvement in its balance of payments through the changes in exchange rates. At the same time, the appreciation of RMB has raised a series of economic and ethical concerns. In fact, the ethical issues and the economic issues are intertwined as the ethical implications depend on the economic impacts of the appreciation. This paper serves as an interdisciplinary study to illustrate the inter-relationship between economics and ethics.

Since the outbreak of the global financial crisis in 2008, the exchange rate between China and USA has drawn a lot of attention. Western countries have exerted great pressure on China to appreciate the RMB. The most controversial issues involve China-USA relationship. For instance, Americans may think that RMB is under-valued so that the balance of payments surplus in China is gained at the expense of the Americans who experience a massive balance of payments deficit. Similarly, it is sometimes claimed that the Chinese workers in the export sectors gain at the expense of the American workers in the import sectors in USA. On the other hand, some well-known economists in USA, including Ben Bernanke and Joseph Stiglitz, have pointed out that appreciation of RMB will not effectively lower the balance of payments deficit in USA since the reduction in imports from China will be replaced by imports from other low-cost countries like Vietnam and Pakistan. The key is to increase the saving rate in USA which is much lower than that in many Asian countries. On the other hand, the current account surplus of China reflects its high national saving rate (Fan 2011). Other than the distributional issue between China and USA, another ethical issue is related to the sovereignty or right of a country to manage its own exchange rate based on the benefit of its citizens. These international issues are very complicated, and there is no universally accepted principle for the distribution of benefits and costs across different nations; even if there were, the distributional effects across nations would be very difficult to measure. Therefore, our study will focus on the economic and ethical issues related to the appreciation of RMB within the boundary of the Chinese economy, including the medium and long run effects.

\section{Major factors affecting the trend of exchange rate of RMB}

We expect an upward trend of RMB exchange rate in general, but the magnitude is difficult to predict. There are several factors that may affect the situation. First, the sustained growth of the economy provides a strong support for the appreciation of RMB. Though the target growth rate of GDP in the 12th 5-year plan has been reduced, it is still at a high level of $7 \%$. With an expectation of high growth, foreign investment in the economy will continue to be strong, providing a solid support for RMB.

Second, if the balance of payment surplus continues to grow, there will be greater pressure for RMB to appreciate. In year 2010, China's current account surplus is 
206.2 billion US dollar (USD), representing a growth of $25 \%$, and the growth in foreign reserve assets is about $18 \%$. This heightens the expectation of appreciation.

Third, some international factors may affect the trend. It is expected that the growth of the US economy will reach 3\%. Its contribution to the growth of the world economy will be bigger than that in year 2010. Comparatively speaking, the growth of the European economy is not optimistic. In the first half of 2010, to repay their debts, Europe's banking industry borrowed an amount of 400 billion Euros. At the same time, European governments also needed 500 billion Euros to pay for their fiscal deficits, plus several hundreds more as collaterals when their bonds will reach maturity. It is possible that the European financial market will have the second round of debt crisis. To maintain financial sustainability, European governments have to reduce their public expenditures. Since unemployment rate is very high, the internal engine for growth is weak. Therefore, the US dollar will perform better than the Euro as an international currency. It is unlikely that devaluation of the US exchange rate will continue for long, there is even a possibility of a reverse trend. Another international factor is that the conflicts over currency exchange rates will affect the RMB exchange rate. Driven by the growth of Asian economies other than Japan, the share of Asian economies (other than Japan) has risen from $16.8 \%$ in year 2000 to $25 \%$ in year 2010 and is expected to rise to $30 \%$ in year 2015 . On the other hand, the share of USA has dropped from $23.6 \%$ to $20.2 \%$ within the same period and will drop further to $18.4 \%$ in year 2015. A large amount of US dollar generated from the quantitative easing policy of USA has flowed into the emerging economies in search of a higher rate of return. Faced with considerable pressure of appreciation caused by the huge inflow of hot money, Asian governments may have to intervene in the market to maintain the stability of economic growth of their countries. This has resulted in the international conflicts over exchange. Capital control and trade restrictions will be considered necessary to protect the national economy.

The fourth factor is the inflation in major world economies, and the differential interest rates among different countries. Even though the US economy may start to recover in year 2011, there are still many obstacles. The Federal Reserve of USA will maintain an easy monetary policy to stimulate its economy. At the same time, the single monetary policy target in European countries is price stability which has constrained inflation rate to $2 \%$, and they are not likely to carry out easy monetary policies. However, when they have to tighten fiscal policies in order to solve their debt crisis, the European Central Bank will have to use monetary policies to maintain a low interest rate. On the other hand, the current nominal interest rate in China is $3.1 \%$, which is attractive to international hot money. Given inflationary expectation, the current interest rate is not high enough to curb inflation, which will continue to rise in the medium term. As China tightens its monetary policy, the interest rate will rise. It is expected that the interest rate differentials between China and the European and USA economies will widen, thus attracting an inflow of capital which puts pressure on the RMB exchange rate.

Fifth, internationalization of RMB may affect the exchange rate. One lesson of the global financial crisis is that an international currency system which is based heavily on US dollar is volatile and risky. China is holding a huge amount of foreign exchange reserves, amounting to about USD 2.65 trillion. A large proportion of it is in US dollar assets. According to the estimation of the US Treasury, up to October 
2010, the value of US Treasury Bonds held by China amounts to USD 906.8 billion, which represents $35 \%$ of the total foreign exchange reserves. Therefore, China is most affected by the depreciation of US dollar and has the incentive to move towards internationalization of RMB. Since July 2009, the use of RMB for the settlement of trade has increased. Recently the volume of daily transaction in the foreign exchange market amounts to about USD 400 million. Even though the scale is relatively small compared with the use of US dollar, Euro, or Japanese Yen, it indicates the emerging role played by RMB in the global foreign exchange market and the determination of the Chinese government to promote the internationalization of RMB.

Sixth, the price of oil is an important factor that could slow down the appreciation of RMB. The international price of oil has jumped from USD 100 per barrel in early 2008 to USD 140. The increase in oil price has an adverse effect on the balance of payments of China which imports around 50\% of its oil. This factor will partially offset the other factors which are favorable to the appreciation of RMB.

Based on the above analyses and the current economic environment, we expect that an appreciation of RMB would be the major trend in the near future, though the magnitude is uncertain. With this background, we will discuss the effect of appreciation of RMB on China.

\section{Effects of appreciation of RMB on China}

An appreciation of RMB would have an impact on the economy and the society as a whole. It will directly affect the export sector, with a negative effect on the volume of export, employment, and also profit. The effects will spread, affecting various sectors and social groups in different directions to a different extent, resulting in redistribution effects. Therefore, the appreciation of RMB is not just an economic problem, but also involves ethical issues. We will analyze the effects of appreciation of RMB in China on six main areas: foreign reserve, import/export sector, employment, inflation, standard of living, and income distribution.

\section{Effect on official foreign exchange reserves}

Theoretically, when RMB appreciates, the value of foreign exchange reserves in terms of the domestic currency will depreciate accordingly. As US dollar assets represent a major share of the official reserves, the loss due to a big depreciation of US dollar can be considerable. The government should plan ahead to minimize the loss due to the appreciation of RMB against the US dollar. Since China has a huge amount of foreign exchange reserves, even if the loss in value is just $1 \%$, it amounts to around USD 5 billion, which is equivalent to about 40 billion RMB. It represents a massive opportunity cost for China as these funds can be used to support education ${ }^{1}$ and improve health care of the poor. The loss in value of foreign exchange reserve due to the appreciation of RMB is of direct concern to the central monetary authority of China. The Peoples' Bank of China and the State

\footnotetext{
${ }^{1}$ It is estimated that the total cost of supporting a child to finish University education is about 500,000 RMB. http://www/cebbank.com/Info/29754329
} 
Administration of Foreign Exchange would find it unacceptable to let this go on without control. The actions they may take draw much attention from both inside and outside of China, and the level of foreign exchange reserves and their structural changes have become signals for possible changes in the exchange rate of RMB.

\section{Effect on import and export sectors}

The appreciation of RMB will increase the international price of China's export, thus reducing its competitiveness. If the price of export is to be kept low, profit will have to be reduced. This will affect many export industries which are mainly labor intensive. The lower profit and even bankruptcy will cause companies to reduce production and employment, resulting in an increase in unemployment of lowskilled workers.

On the other hand, the volume of import is expected to increase since imported consumer products and raw materials will be cheaper in China. The overall effect on the balance of payments depends on the elasticities of demand for import and export. It will deteriorate only if the sum of the elasticities is greater than one (MarshallLearner condition). Otherwise, the balance of payments will actually increase upon the appreciation of RMB (Wang 2010).

Currently, the majority of the export-oriented industries is labor intensive, and US dollars are used for payments. With an appreciation of RMB, the profit of these industries will decrease. Unlike capital and skill intensive industries which can absorb the loss in cost advantage by other advantages, the value added for laborintensive industries is relatively low. So their competitiveness is much affected by the loss in cost advantage.

However, some economists think that the effect of the appreciation of RMB on export industries may not be very serious. It is estimated that for a $10 \%$ appreciation, the burden on the exporters in China and consumers in foreign countries, respectively, is about 5\%. A similar empirical study also finds that the price elasticity of export is around -0.6. Based on these estimates, if the effective exchange rate of RMB (which is linked to a basket of currencies) appreciates by 5$6 \%$, the profit of export sector will at most go down by $1.5-1.8 \%$, even assuming that the industries do not respond by raising productivity.

Besides, the structure of export in China is such that more than $55 \%$ are export processing. When the prices of exports are raised because of RMB appreciation, the costs of imported materials are lowered at the same time. Therefore, the sensitivity of this sector to an appreciation of the exchange rate is lower than other export industries. At any rate, a restructuring of the export sector to lower cost of production and to increase efficiency can be effective means to reduce the negative effect of the appreciation of exchange rate.

\section{Effect on employment}

The Chinese economy is export-oriented. According to the official statistics in year 2009 , the proportion of exports and imports to GDP amounts to almost 70\%. Export has become one of the most important driving forces for the growth of employment and the economy. In the same year, the value of export alone was USD 593.4 billion; 
the trading industries employed around 70 million workers. From these numbers, one may conclude that the effect of the appreciation of RMB on reducing export and thus employment could be considerable. In fact, the impact of appreciation on different industries will be different, depending on the extent of import dependence. Moreover, the structure and the nature of products, and profit margins are different across industries and enterprises, and thus, their sensitivities to changes in exchange rate will also vary. For instance, we have explained earlier that the sensitivity of the export-processing industries is lower than other export industries.

We can classify industries into four types according to the extent and nature of the effect: industries with large adverse effects, industries with little adverse effects, industries with neutral effects, and industries with favorable effects. The first type consists mainly of labor-intensive industries, like textile and clothing, shoe making, toys, motor cars, furniture, lighting, and bicycles, and also agricultural industries and industries with relatively large export dependence. It has been estimated that the affected employment may be more than ten million workers. The effect on agricultural sector is especially notable. In recent years, the major agricultural products for export and import are beans, cotton, corn, and wheat. In year 2009, the total area used for the growing of these four types of agricultural products amounts to 60.85 million acres. This takes up about $40 \%$ of total agricultural land, involving an agricultural work force of 100 million. If RMB exchange rate appreciates by $10 \%$, there will be a large decrease in the domestic price of these agricultural products, leading directly to a decrease in demand for these domestically produced products in both the domestic and international market, adversely affecting the employment and income of the agricultural sector.

In summary, an appreciation of RMB will exert much pressure on the labor market. The effect is especially great in labor-intensive industries, and the burden will be largely borne by labor in terms of reduced employment opportunities. On the other hand, this may provide an opportunity for an improvement in the structure of employment by a shift towards higher skilled employment.

\section{Effect on inflation}

Since 2010, the rate of increase in the Consumer Price Index in China has hovered around $4 \%$. Therefore, one of the major problems in the Chinese macro-economy is to prevent inflation. In general, an appreciation of the exchange rate leads to a fall in the prices of imported good and factors of production, thus reducing the cost of production. We might expect the price level to decrease. Why is this decrease not observed in China? The major reason is that there has been a large influx of international financial capital into China as the appreciation of the currency generates expectation of further appreciation. The supply of money in China increases when the foreign currencies are converted to RMB, and China's foreign exchange reserves increase. The increase in money supply leads to an increase in price level. The Chinese government has to keep on buying foreign currencies with $\mathrm{RMB}$ to control the appreciation of the RMB and issue government bonds to absorb the excess liquidity of $\mathrm{RMB}$ in circulation in the market to control inflation. Nonetheless, the appreciation of RMB may have a favorable direct effect on imported inflation, since the cost of imported goods and raw materials are now cheaper. 


\section{Effect on standard of living}

An appreciation of the RMB may have some favorable medium- and long-term effects on the standard of living. The price of import will be lower, as the Chinese people can use the same amount of RMB to buy more imports. Besides, traveling and studying aboard will be cheaper. But the effect of the above may not be felt by the general public. China exercises foreign exchange control; there are strict restrictions for people to exchange for foreign currencies to buy foreign assets. Even though RMB has appreciated in the international market, it would not affect the wealth of common people, nor will it have much effect on interest rates. On the other hand, an appreciation of RMB will have an adverse effect on export and employment as discussed above, which may hurt the common people. One other effect of appreciation on the standard of living of the common people is its possible effect on the price of housing in the property market. If there is expectation that the trend of the appreciation of RMB will continue, an inflow of foreign capital will be attracted, and some of it may be drawn to the property market, causing an overheating of the property market and a fast increase in property prices. The common people will find properties less affordable given that their incomes are not raised correspondingly. Besides, when the problem of inflation gets more serious or out of control, the purchasing power of common people is reduced and it will be difficult to maintain their standard of living.

\section{Effect on income distribution}

Following various policy reforms on marketization of the Chinese economy, income inequalities in China have been widening so that it has become one of the most unequal countries in the world. In year 2000, the Gini coefficient exceeded 0.4, the international warning level, and reached 0.47 in year 2009. The income inequality problem is regarded as one of the most serious problems in China, and any exchange rate policy has to take into consideration its possible effect on income inequality. There is no consensus on the effect of appreciation on income distribution. For example, a few years ago Stiglitz cautioned about the appreciation of RMB because of its adverse effects on the rural sector as the prices of domestic agricultural products would be depressed by the lower prices of imported agricultural products. But now, global food prices are increasing and the burden of higher food prices on urban workers and inflationary pressure in general become the major concern. In this context, RMB appreciation could reduce inflationary pressure and the threat to the real income of urban worker, while rural workers enjoy an increase in income due to rising food prices (Stiglitz 2011).

Some researchers suggest that an appreciation of RMB would aggravate the inequality problem; imports get cheaper but a lot of imported goods are luxurious consumer goods; thus, the wealthy and not the poor people gets the benefit of the lower imported prices. Other than enjoying lower prices for imported goods, the rich people can also enjoy lower prices of imported services like traveling abroad. The real income of the rich actually increases more than the poor because of appreciation. On the other hand, an appreciation of RMB may reduce the inequality problem, since it is the rich who holds foreign currencies and assets, whose value 
depreciates when RMB appreciates. However, when we take into the adverse effect of appreciation of RMB on labor-intensive industries and employment, it is likely that the overall distributional effect will be negative.

\section{Ethical implications of the appreciation of RMB and suggested policies}

The economic effects of the appreciation of RMB have several ethical implications. The foreign exchange reserves in China are accumulated as a result of the trade surplus over the years, which reflect the accumulation of national saving. Running a continuous balance of trade surplus is equivalent to a continuous lending by the Chinese people to their trading partners who run a continuous balance of payment deficit. When the appreciation of RMB leads to a huge decrease in the value of foreign exchange reserves in terms of $\mathrm{RMB}$, it would impose a great opportunity cost to China since the resources could have been used in many meaningful ways to promote equality and opportunities for the poor, such as improving their education and health care. It is therefore the responsibility of the Chinese government towards its own citizens to safeguard the value of its national savings by implementing a prudent exchange rate policy. The father of Euro Robert Mundell voiced his objection against international pressure to force RMB to appreciate. He pointed out that appreciation may not reduce the balance of trade surplus either theoretically or empirically. Therefore, RMB exchange rate should be maintained at a stable level. He further remarked that if there are large fluctuations in the exchange rate between RMB and the US dollar, they will cause not only a lot of damage to China, but also much instability to the global economy (Mundell 2010). The ethical consideration concerning the right magnitude of RMB appreciation thus depends on the extent of its economic impact.

Our study has shown that an appreciation of RMB would affect different industries to a different extent. It is likely that labor-intensive industries would suffer most, and low-skilled workers in these industries would be adversely affected, especially the low income urban workers who do not have job securities and do not own properties. When the export sector becomes less competitive upon appreciation of RMB, some of their workers may lose their jobs; at the same time, they would be hard-pressed by the rising property prices. The rural agricultural sector is also very vulnerable. In China, the standard of living of the rural sector is much lower than that in the urban sector. Therefore, the interest of the rural sector should be given priority on ethical grounds in the design of exchange rate policies.

In view of the economic and ethical problems in relation to the appreciation of RMB, we now offer some policy suggestions which might alleviate the problems. First, the government should consider using appropriate fiscal intervention to reduce the adverse distribution effect of the appreciation of RMB. It is advisable to increase public construction which can reduce the pressure of unemployment on the one hand and increase internal demand on the other. Second, industries should be restructured and the process of upgrading speeded up to increase their competitiveness. When RMB appreciates, exports become less competitive in the international market. This will impose a challenge to the low-cost model of export. Industries should now strengthen their capacity for innovation, increase the value added of production, and 
increase their skill intensity so as to increase their competiveness. Besides, the model of economic development should change from extensive to intensive growth. China should phase out those industries with inefficient use of energy and encourage industries which are innovative and employ advanced technology. Third, the internal market should be expanded to avoid over-dependence on the international market. Export, investment, and consumption are the three leading driving forces of development. Currently, both investment and export are affected adversely by the financial crisis. While there is a heavy pressure for RMB to appreciate, it would be wise for China to turn to internal demand for its sustained growth, especially to increase domestic consumption to reduce the trade surplus, which at the same time can improve the standard of living of consumers. This strategy is feasible since the continuous rapid growth of the economy over many years and the accompanying high saving rate have created a great potential for its domestic demand to increase. Fourth, the structure of foreign exchange reserves can be improved. Currently, US dollar is the major component of its foreign exchange reserves. This overrepresentation of US dollar puts the official foreign exchange reserves to great risk. The composition of foreign exchange reserves should be re-balanced to increase the weight of other major currencies. Fifth, for risk-diversification, exporting industries should use more hard currencies other than US dollar as a transaction currency, and at the same time, the use of RMB as an international currency should be promoted.

\section{References}

Fan, Gang. (2011). “China’s Shrinking Trade Surplus”, Project Syndicate, 2011-01-03.

Mundell, R. (2010). 罗伯特·蒙代, 现阶段让人民币升值是大错特错 (Letting Renminbi appreciate in the present stage is a big mistake), IT Time Weekly, 2010-8-20.

Stiglitz, J. E. (2011). "Remarks for the China's leadership", China Development Research Foundation website, 2011-01-11. http://www.cdrf.org.ch.

Wang, Q. (2010). 王 菁, 人民币升值利弊分析 (An analysis of the pros and cons of the appreciation of Renminbi), 现代商贸工业, 第9期. 